\title{
Practical Advantages of Multivariable Control Strategy for Off-Grid Variable- Speed Variable-Pitch (VS-VP) Wind Turbines
}

\author{
S. Fragoso ${ }^{1}$, F.Vázquez ${ }^{1}$, F. Morilla ${ }^{2}$ \\ ${ }^{1}$ Department of Computer Science and Numerical Analysis, University of Córdoba, Campus of Rabanales, Building \\ Leonardo Da Vinci, 14071, Córdoba (Spain) \\ Phone/Fax number: +34957218729, e-mail: p52frhes@uco.es
}

${ }^{2}$ Department of Computer Science and Automatic Control, UNED, Juan del Rosal 16, 28040, Madrid (Spain)

\begin{abstract}
The design of variable speed wind turbine control systems is a hard challenge where a nonlinear multivariable process with high disturbances, restrictions and interaction between variables appears. Under that situation, a reliable and powerful control strategy is needed to achieve a maximum performance. In this paper a multivariable control scheme based on a torque controller and pitch angle controller for a VS-VP small wind turbine connected with a permanent-magnet DC generator (PMG) is proposed. Both controllers are tuned for operating in several wind speed regions. Simulation results show the robustness, effectiveness and benefits of the multivariable control strategy used for different operation situations. The multivariable controller is compared with other baseline control schemes such as LQG controller and standard switched controller.
\end{abstract}

\section{Key words}

Wind turbines, VS-VP, Power Converter, Multivariable Control.

\section{Introduction}

Wind energy has experienced a high growth to world level since final 90's. The world capacity achieved $239 \mathrm{GW}$ in 2011 and a growth about $100 \mathrm{GW}$ is foreseen by the end of 2013 [1]. In late 2011 the production of energy because of the wind force achieved 430 TWh, which supposed 2.5 $\%$ of full energy coverage to world level [2]. That statistics show how wind energy is a consolidated technology inside the mix of electricity generation and it has became the spotlight of the field of control engineering.

Traditionally and mainly due to its good performance, the wind turbines have been controlled through monovariable control strategies (SISO) [3]. Nevertheless this regulation can produce vibrations in the mechanical structure, excessive noise and low power efficiency [4]. In addition when the wind speed has a high turbulent component, usually high fluctuations appear in the output variables. In this point the following question could be formulated: would it be possible the use of more complex control strategy with multivariable character which would allow reducing the undesirable effects of the SISO strategies?

The aim of this work is in the direction of answering the previous question. For this, it is therefore necessary to apply the multivariable control scheme on a particular wind turbine model and thereby to obtain conclusions.

A classical model of wind turbine of $7.5 \mathrm{~kW}$ working in off-grid mode is considered and simulated to represent the rectifier-coupled permanent magnet alternator, typical to direct drive small turbines [5]. The wind turbine directly deliveries energy to a load through an electronic converter which has the role of step-down DC-DC converter. This wind turbine is modelled coupled to a permanent-magnet DC generator.

This model has been selected by the authors because of it presents similar structural characteristics (permanentmagnet DC generator without gearbox) to an experimental off-grid VS-VP small wind turbine placed in the laboratories of the Department of Computer Science and Numerical Analysis at the University of Córdoba. The implemented multivariable control strategy over experimental system will be support by the obtained results in this paper.

The control strategy is performed in two steps. First of all, a decentralized multivariable scheme is used to control the two involved variables, the angular speed and the electrical power. Then, an upper layer is added including an algorithm of maximum power point tracking (MPPT) (Fig. 1). 


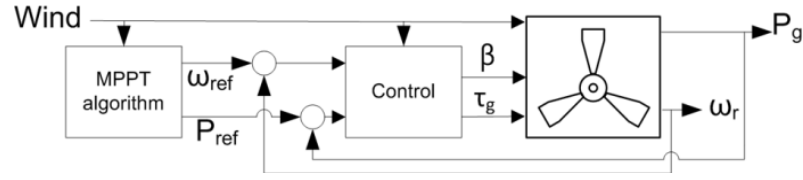

Fig. 1. Multivariable control scheme with MPPT algorithm

In order to evaluate the wind turbine performance with the proposed controller, mathematical nonlinear models of the wind turbine as well as a model to generate the signal of the wind are used. The paper presented is organized as follows: functional description of wind turbines is shown in Section 2. The mathematical model of wind turbine is presented in Section 3. In Section 4 the design of multivariable controller and other SISO baselines control strategies are explained. Section 5 shows a comparative analysis between SISO and MIMO controllers. Finally, the conclusions are discussed in Section 6.

\section{System description}

Wind energy conversion systems (WECS) present several operating modes according to the pitch control of blades angle (variable pitch, VP, or fixed pitch, FP) and according to the generator speed control (fixed, FS, or variable, VS). The strategies called Variable-Speed Variable-Pitch (VS-VP) are the best choice to achieve the control goals to operate in all regions. The VS wind turbines use the high inertia of rotor and generator as flywheel to soften the power's fluctuations thus reducing mechanical stress of drive train [6]. In this operation mode electronic converters such as Step-down/Step-up Converters or Variable Frequency Drives (VFD) are inserted between the generator and the grid or load, insomuch as a variable-speed operation mode of wind turbine requires a variable-speed feature of electrical generator.

VS-VP wind turbines have five principal operation regions in which the wind turbine should be driven effectively to extract the wind power while at same time maintaining a safe operation. These regions are related with the wind speed as Fig. 2 illustrates.

In region I the wind speed is too low to drive the wind turbine, so that it is stopped to avoid mechanical wear. In the region II, called partial load region, the wind turbine operates to below-rated wind speed trying to achieve of maximum power. In this area, MPPT (Maximum Power Point Tracking) algorithms are used to obtain tracking setpoints for output variables [7]. In this region the classical PID strategies acts over generator torque whereas the pitch is kept constant in an optimum fixed value. There are two alternatives for the generator torque control in this area: either power feedback control or speed feedback control. In both cases a generator torque control exists whose main goal is to follow the set-points generated by MPPT algorithm. PID strategy inside this region can experience high fluctuations because of the highly nonlinear characteristics of wind turbine. These fluctuations are mainly due to interaction existing between variables which is not corrected with only a single controller [8]. The fluctuations appear clearly in the transition region III.

In the region IV, or full load region, the wind turbine has achieved rated electric power and the controller must limit and smooth this power. In this case, PID control strategy is changed and now the generator torque is kept constant and the pitch angle begins operating to avoid the wind turbine overloading.

Finally, the region $\mathrm{V}$ is a critical zone because of the wind speed has achieved a high level that could cause mechanical and structure damage in the wind turbine so that it is necessary to stop driving.

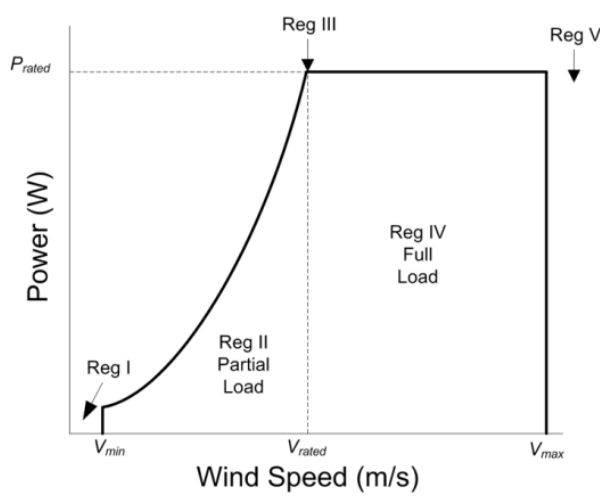

Fig. 2. Operation regions of wind turbine

\section{Wind Turbine Model}

This section shows a VS-VP small wind turbine model of $7.5 \mathrm{~kW}$ which is coupled to a permanent-magnet DC generator. Also the developed wind speed model is presented which is used to obtain more realistic simulation results. The simulations have been done with the technical parameters of the wind turbine described in [5].

The aerodynamic torque $\tau_{a}$ is generated by the wind forces and it depends on the aerodynamics properties of the turbine: shape, size, blade's orientation, as well as, speed, direction and density of wind. This torque $\tau_{a}$ in the rotor is given by the nonlinear expression (1)

$$
\tau_{a}=\frac{1}{2} \rho \pi R^{3} \frac{C_{p}(\lambda, \beta)}{\lambda} v^{2}
$$

where $\mathrm{R}$ is the rotor radius, $\rho$ is the air density and $v$ is the wind speed. The power coefficient $C_{p}$ depend on the blade pitch angle, $\beta$, and the tip-speed ratio $\lambda$, which is defined as the ratio between the linear blade tip speed and the wind speed.

$$
\lambda=\frac{\omega_{r} R}{v}
$$

The power coefficient $C_{p}$ can be experimentally obtained, however in this case it is modelled on through the nonlinear analytical expression [9] as follows:

$$
C_{p}(\lambda, \beta)=c_{1}\left(\frac{c_{2}}{\lambda_{i}}-c_{3} \beta-c_{4} \beta^{c_{5}}-c_{6}\right) e^{\frac{-c_{7}}{\lambda_{i}}}
$$




$$
\lambda_{i}=\left[\left(\frac{1}{\lambda+c_{8} \beta}\right)-\left(\frac{c_{9}}{\beta^{3}+1}\right)\right]^{-1}
$$

with coefficients $c_{1}=0.73, \quad c_{2}=151, \quad c_{3}=0.58$, $c_{4}=0.002, \quad c_{5}=2.14, \quad c_{6}=13.2, \quad c_{7}=18.4, \quad c_{8}=$ $-0.02, c_{9}=-0.003$.

Assuming a rigid low speed shaft, a one-mass model is considered and the inertia moment of the rotation mechanism results:

$$
J_{t} \frac{d \omega_{r}}{d t}=\tau_{a}-B_{t} \omega_{r}-\tau_{g}
$$

where $J_{t}$ is the total inertia moment that includes the turbine inertia and the inertia of generator. $B_{t}$ is the total viscous friction coefficient and $\tau_{g}$ is the generator torque.

\subsection{Electric Generator}

The electric generator receives in its high speed shaft the angular speed of rotor $\omega_{r}$ multiplied by the transmission gearbox $N$. The output is the armature current $i_{a}$. The dynamic of armature current is:

$$
\begin{gathered}
L_{a} \frac{d i_{a}}{d t}=E_{a}-v_{a}-R_{a} i_{a} \\
E_{a}=k \varphi N \omega_{r}
\end{gathered}
$$

where $L_{a}$ is the armature inductance, $R_{a}$ is the armature resistance, $v_{a}$ is the output voltage of electric generator, $E_{a}$ is the back e.m.f. generated in the armature, $k$ is the generator constant and $\varphi$ is the magnetic field flux. For an electric generator, the output power $P_{g}$ and generated torque $\tau_{g}$ are related variables (16). The generated torque is the result of the electromagnetic torque multiplied by the transmission gearbox (8). The generated electromagnetic torque can be expressed in relation with the armature current (9)

$$
\begin{gathered}
\tau_{g}=N \tau_{e m} \\
\tau_{e m}=k \varphi i_{a}
\end{gathered}
$$

Equation (9) shows that the electromagnetic torque can be modified via controlling flux $\varphi$ or by controlling armature current $i_{a}$. The electromagnetic torque in a permanentmagnet dc generator can only be controlled by adjusting the armature current since the field flux is constant. In order to simplify the electrical generator model, a pure resistance load $R_{L}$ has been considered (10).

The armature current flows across the resistance load and it can be controlled by setting the DC voltage across this resistance. Thus, a DC-DC converter is needed to control the output power of electric generator [10]. The incorporation of power converter in the model is expressed in (11).

$$
v_{o}=\alpha v_{a}
$$

$\alpha$ represents the simplified effect of duty-cycle of stepdown DC-DC converter inserted between the resistance load and the output generator. The new variable $\alpha$ which is named load modulation index is considered as an input variable in the multivariable control strategy. The direct torque control, shown in Fig. 1, will be replaced for an indirect torque control through the load modulation index.

\subsection{Nonlinear Model}

In summary and from equations (1)-(11), the following nonlinear model of the wind turbine is obtained.

$$
\begin{gathered}
J_{t} \frac{d \omega_{r}}{d t}=\tau_{a}-B_{t} \omega_{r}-\tau_{g} \\
\tau_{a}=\frac{1}{2} \rho \pi R^{3} \frac{C_{p}(\lambda, \beta)}{\lambda} v^{2} \\
L_{a} \frac{d i_{a}}{d t}=k \varphi N \omega_{r}-v_{o}-R_{a} i_{a} \\
\tau_{g}=N k \varphi i_{a} \\
P_{g}=\tau_{g} N \omega_{r}
\end{gathered}
$$

\subsection{Wind speed model}

The wind speed is a natural phenomenon which can be modelled by a stationary stochastic process composed of a media speed $v_{w m}$, gusts $v_{w g}$, turbulences $v_{w t}$ and ramps $v_{w r}[11]$.

$$
v_{w}(t)=v_{w m}+v_{w r}(t)+v_{w g}(t)+v_{w t}(t)
$$

The turbulent component $v_{w t}$ is described by the Van Der Hoven model in [12].

\section{Control System}

\subsection{Baseline Control Strategies}

\section{A. Torque Control combined with Pitch Control (Standard Switched Control)}

As discussed in Section 2, when initially the wind speed is enough low to operate in the region II the control is based in a torque control. The optimum torque is calculated through a quadratic function of speed (18),(19). When the wind speed achieves the transition region III, the torque control signal is saturated and the pitch control takes over through PID control to limit turbine power (21),(22) [13].

$$
\begin{gathered}
\tau_{g}=f\left(\widehat{\omega}_{r}\right) \\
f\left(\widehat{\omega}_{r}\right)=K \widehat{\omega}_{r}^{2}
\end{gathered}
$$

$$
v_{a}=R_{L} i_{a}
$$


$\widehat{\omega}_{r}$ is the measurement of the rotor speed, and $K$ is given by (20)

$$
K=\frac{1}{2} \rho \pi R^{5} \frac{C_{p o p t}}{\lambda_{o p t}^{3}}
$$

where $C_{\text {popt }}$ is the maximum power coefficient achievable by the turbine, and $\lambda_{\text {opt }}$ is the tip speed ratio at the maximum power coefficient.

$$
\begin{gathered}
\beta(t)=K_{p}\left(e(t)+\frac{1}{T_{i}} \int_{0}^{t} e(\tau) d \tau+T_{d} \frac{d e(t)}{d t}\right) \\
e(t)=P_{g_{\text {rated }}}-\hat{P}_{g}
\end{gathered}
$$

$\widehat{P}_{g}$ is the measurement of the electric power

\section{B. LQG Control}

LQG control is another classical approach of control and it is based on extended linear representation in state-space model over an operation point [14]. The wind power capture optimization and load torque fluctuation goals can be taken into account by minimizing the following cost function:

$$
J_{c}=\lim _{T \rightarrow \infty} E\left\{x^{T}(t) Q x(t)+u^{T}(t) R u(t) d t\right\}
$$

where $x(t)=\omega_{r}(t)$ and $u(t)=\tau_{g}(t)$

$Q$ must be a non-negative definite matrix and $R$ is a positive definite matrix. The control which minimise the cost function $J_{c}$ is given by the linear feedback law, such as follows:

$$
\begin{gathered}
u(t)=-L x(t) \\
L=R^{-1} B^{T} S
\end{gathered}
$$

where $S$ is the only positive definite solution of the algebraic Riccati equation (26)

$$
\tilde{A}^{T} S+S \tilde{A}-S \tilde{B} R^{-1} \tilde{B}^{T} S+Q=0
$$

where $\tilde{A}$ and $\tilde{B}$ are the augmented matrices of state-space model due to the integrated reference error.

\subsection{Multivariable Control}

The multivariable approach proposed by the authors has been a decentralized control whose scheme is shown in Fig. 3. The transfer functions (27) and (28) represent the apparent processes which depend on both the direct transfer function and the applied influence for the other control-loop [15].

Main objective of multivariable strategy is to reduce the variations over the set-point of output variables and to improve the performance of the WECS. Such variations are the result of the existing interaction produced by the changes in the wind speed intensity. Furthermore the multivariable control approach pursues to obtain better results in the transitions between the operating regions.

$$
\begin{aligned}
& \tilde{g}_{1}(s)=g_{11}(s)-\frac{k_{2}(s) g_{12}(s) g_{21}(s)}{1+k_{2}(s) g_{22}(s)} \\
& \tilde{g}_{2}(s)=g_{22}(s)-\frac{k_{1}(s) g_{12}(s) g_{21}(s)}{1+k_{1}(s) g_{11}(s)}
\end{aligned}
$$

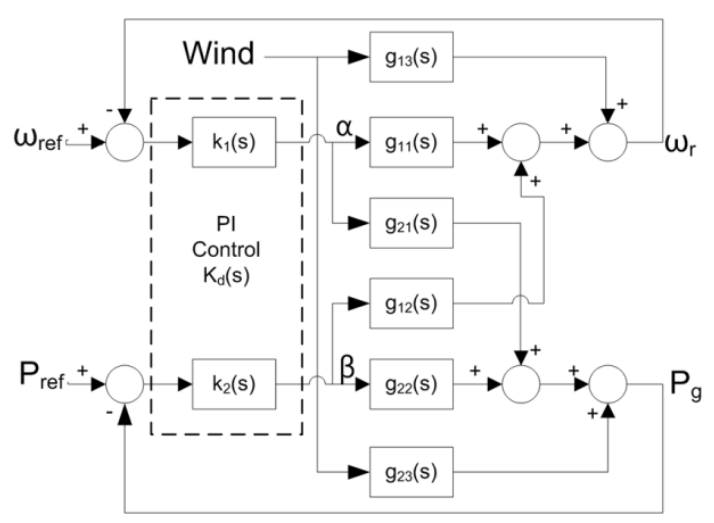

Fig. 3. Decentralized multivariable controller block scheme

Starting from the linearization of model at various operating points, and using a computational tool the controllers have been designed with PI structure. The decentralized controller $K_{d}(s)$ is defined as follows:

$$
\begin{aligned}
K_{d}(s) & =\left[\begin{array}{cc}
k_{1}(s) & 0 \\
0 & k_{2}(s)
\end{array}\right] \\
k_{1}(s) & =k_{p 1}\left(1+\frac{1}{t_{i 1} s}\right) \\
k_{2}(s) & =k_{p 2}\left(1+\frac{1}{t_{i 2} s}\right)
\end{aligned}
$$

The controller $K_{d}(s)$ has been tuned using an iterative process developed into the computational tool [16].

$$
\begin{aligned}
& k_{p 1}=0.00346 \% / \mathrm{rad} / \mathrm{s}, t_{i 1}=12.6 \mathrm{~s} \\
& k_{p 2}=-0.00205 \mathrm{deg} /{ }_{W}, t_{i 2}=7.07 \mathrm{~s}
\end{aligned}
$$

\section{Simulation Results}

Fig. 4 shows a first simulation of the closed loop system which compares the decentralized multivariable control strategy with the baselines control strategies. The simulation corresponds to a wind speed where the wind turbine operates in the partial load region. The wind speed has a mean value component of $8 \mathrm{~m} / \mathrm{s}$ at the hub height added to turbulent component with $0.35 \mathrm{~m} / \mathrm{s}$ of standard deviation. In the operating point, the rotor speed reference set-point is $169.49 \mathrm{rad} / \mathrm{s}$ and the power reference set-point is $4373.8 \mathrm{~W}$. The wind turbine model is very sensitive to wind speed changes, which principally is reflected in the power characteristic. 
Because of the presence of a blade pitch control in conjunction with the indirect torque control in the multivariable strategy, the standard deviation of rotor speed and generated power as well as the deviation of control loads are lower than the deviations obtained with the baseline strategies, (Table I).
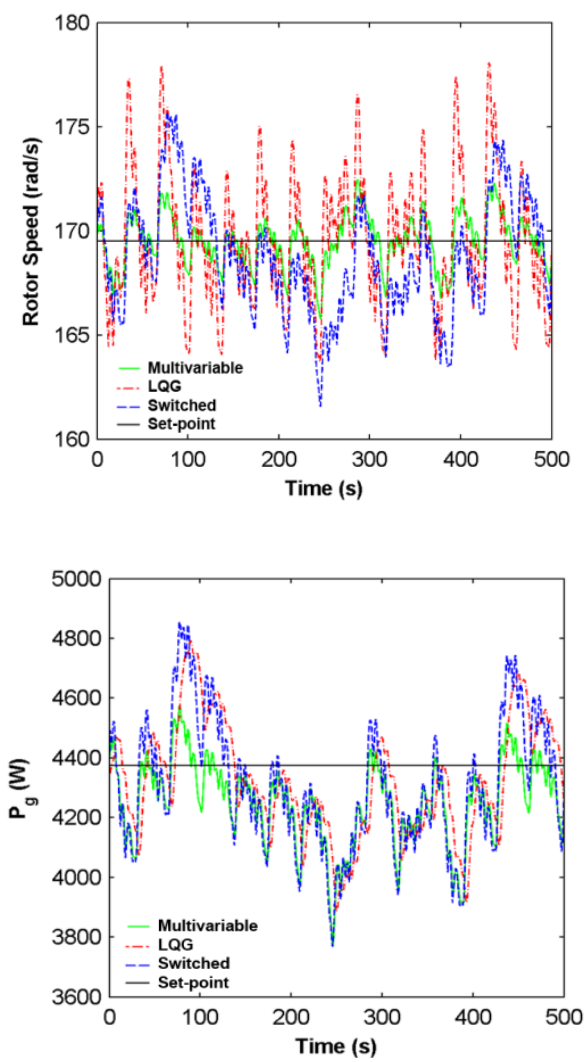

Fig.4. Comparison between strategies at partial load region

Table I.-Comparison of the control variable and control loads in the region II

\begin{tabular}{|c|c|c|c|}
\hline & Switched & LQG & Multivariable \\
\hline Mean & & & \\
\hline $\bar{T}_{g}(\mathrm{Nm})$ & 243.22 & 250.27 & 239.35 \\
\hline $\bar{\beta}(\mathrm{deg})$ & 0 & - & 0.226 \\
\hline $\bar{P}_{g}(\mathrm{~W})$ & 4300.3 & 4320 & 4247.9 \\
\hline $\bar{\omega}_{r}(\mathrm{rad} / \mathrm{s})$ & 168.735 & 169.448 & 169.451 \\
\hline $\begin{array}{c}\text { Standard } \\
\text { Deviation }\end{array}$ & & & \\
\hline$S d\left(\bar{T}_{g}\right)(\mathrm{Nm})$ & 8.171 & 10.836 & 6.708 \\
\hline$S d(\bar{\beta})(\mathrm{deg})$ & 0 & - & 0.303 \\
\hline$S d\left(\bar{P}_{g}\right)(\mathrm{W})$ & 216.447 & 192.879 & 142.106 \\
\hline$S d\left(\bar{\omega}_{r}\right)(\mathrm{rad} / \mathrm{s})$ & 2.8050 & 3.0953 & 1.2435 \\
\hline
\end{tabular}

In the second simulation the wind turbine is operating in the full load region at the rated rotor speed and rated power. The wind speed profile has a mean value of 9.7 $\mathrm{m} / \mathrm{s}$ with a turbulent component with $0.1 \mathrm{~m} / \mathrm{s}$ of standard deviation. This ensures that the wind turbine has achieved an operating point where both the rotor speed and generated power exceed their rated values, $200 \mathrm{rad} / \mathrm{s}$ and $7500 \mathrm{~W}$ respectively.
Table II shows that the multivariable control strategy also presents better results in respect with deviation of control loads and standard deviations than the baseline strategies.

Table II.-Comparison of the control variable and control loads in the region III

\begin{tabular}{|c|c|c|c|}
\hline & Switched & LQG & Multivariable \\
\hline Mean & & & \\
\hline $\bar{T}_{g}(\mathrm{Nm})$ & 340.23 & 365.46 & 358.080 \\
\hline $\bar{\beta}(\mathrm{deg})$ & 1.341 & - & 0.464 \\
\hline $\bar{\omega}_{r}(\mathrm{rad} / \mathrm{s})$ & 199.775 & 199.995 & 200.001 \\
\hline $\bar{P}_{g}(\mathrm{~W})$ & 7.118 .2 & 7110.4 & 7499.7 \\
\hline $\begin{array}{c}\text { Standard } \\
\text { Deviation }\end{array}$ & & & \\
\hline$S d\left(\bar{T}_{g}\right)(\mathrm{Nm})$ & 2.425 & 3.720 & 1.231 \\
\hline$S d(\bar{\beta})(\mathrm{deg})$ & 0.043 & - & 0.157 \\
\hline$S d\left(\bar{\omega}_{r}\right)(\mathrm{rad} / \mathrm{s})$ & 1.427 & 1.121 & 0.232 \\
\hline$S d\left(\bar{P}_{g}\right)(\mathrm{W})$ & 96.118 & 77.804 & 33.594 \\
\hline
\end{tabular}

\subsection{Transition simulation between operation regions}

In this section, the wind turbine operates under more realistic wind speed conditions with a single controllers tuning. In this case the wind profile has a sine wave component with mean value of $8 \mathrm{~m} / \mathrm{s}$ and $2 \mathrm{~m} / \mathrm{s}$ of amplitude added to a turbulent component of $0.1 \mathrm{~m} / \mathrm{s}$. This wind speed profile causes the operating point of wind turbine is moved continuously across the three operation regions established.

When the system is working in sub-rated points, a variable reference set-point is imposed. The reference is obtained with a Maximum Power Point Tracking (MPPT) algorithm. The MPPT algorithm is based on wind-speed measurement and it supplies the optimum reference setpoint of rotor speed and electrical power. Internally the optimum rotor speed and optimum power are calculated using the values of maximum power coefficient and tipspeed ratio in which that coefficient is produced. If the optimum reference set-points calculated exceed the rated values then the reference set-points are changed.

As it is shown in Fig. 5, the decentralized multivariable control can keep a power coefficient very closed to theoretical maximum value 0.441 during the operation in the partial load zone while avoiding excessive overshoot output variables on the rated values.

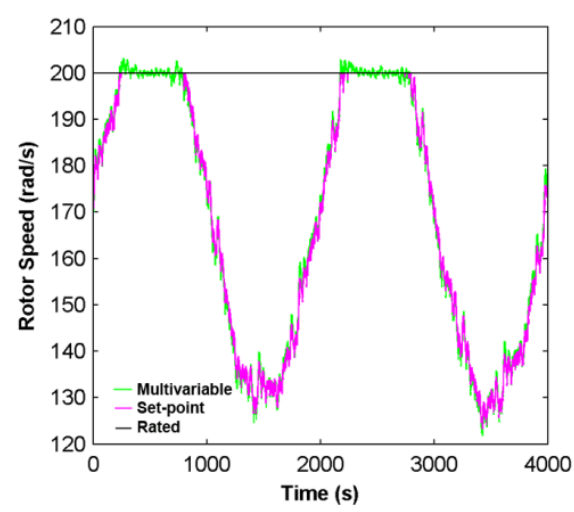



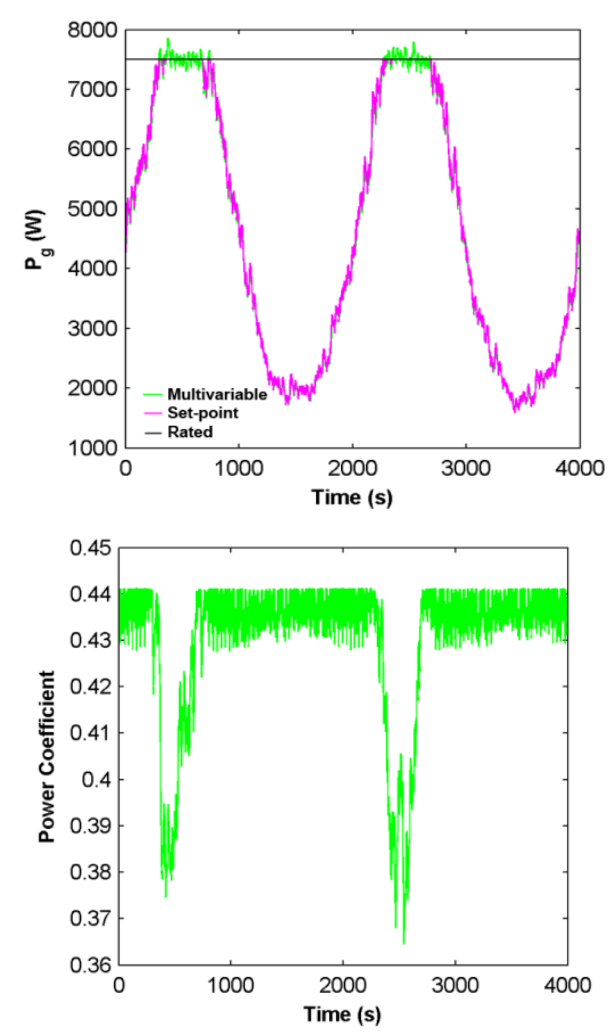

Fig. 5. Wind turbine output register with realistic wind speed conditions

\section{Conclusion}

In this paper a nonlinear mathematical model has been developed with the technical data from VS-VP small wind turbine of $7.5 \mathrm{KW}$. With the linearization of the model in different operating points a single decentralized controller has been designed.

The proposed decentralized multivariable control strategy proposed has been compared with another monovariable baseline control strategies thus obtaining statistical data of the performance. These data show the multivariable control strategy presents better results about standard deviation in control loads and output variables.

Furthermore, a wind speed model has been studied and developed in order to achieve more realistic and precise results of wind turbine output register. This wind speed model has allowed simulating a test where the wind turbine is subjected both a variable wind speed profile and variable reference set-point. With the complement of MPPT algorithm the multivariable scheme leads to good performance even in rotor speed and generated power in the complete range of wind speed.

\section{Acknowledgments}

This work was supported by the Autonomous Government of Andalusia (Spain), under the Excellence Project P10TEP-6056. This support is very gratefully acknowledged.

\section{References}

[1] World Wind Energy Association, World Wind Energy Report 2010, WWEA Head Office, Bonn, Germany 2011.

[2] Asociación Empresarial Eólica, Anuario 2012, (2012).

[3] Muljadi E, Pierce K, Migliori P, “A Conservative Control Strategy for Variable-Speed, Stall Regulated Wind Turbine", Proceedings of the $19^{\text {th }}$ ASME Energy Symposium, Reno, Nevada. (2000)

[4] F. Martinez, L. Herrero, S. Gómez and J. González, "Analysis of the Efficiency Improvement in Small Wind Turbines when Speed is Controlled. In Industrial Electronics”, ISIE IEEE International Symposium, Cambridge, UK, 2007, pp 437-442.

[5] M. J. Khan and M. T. Iqbal, "Analysis of a Small Wind-Hydrogen Stand-Alone Hybrid Energy System”, Applied Energy. (2009), Vol 86, pp 2429-2442.

[6] J. L. Rodriguez, J. C. Burgos, and S. Arnalte, Sistemas Eólicos de Producción de Energía Eléctrica, first ed., Editorial Rueda,Madrid, 2003.

[7] S. Barakati, M. Kazerani, J.D. Aplevich, "Maximum Power Tracking for the Wind Turbine Systems Including a Matrix Converter", IEEE Transaction on Energy Conversion, (2009), Vol 24, pp 705-713.

[8] M. González, F. Vázquez, and F. Morilla, “Control Multivariable Centralizado con Desacoplo para Aerogeneradores de Velocidad Variable”, Revista Iberoamericana de Automática e Informática Industrial, (2010), Vol 7, pp 53-64.

[9] T. Ackerman. Wind Power in Power Systems. John Wiley \& Sons, Chichester, UK, 2005.

[10] A. Merabet, J. Kerr, V. Rajasekaran, D. Wight, "Power Electronics Circuit for Speed Control of Experimental Wind Turbine”, In $24^{\text {Th }}$ International Conference on Microelectronics, Algiers, Algeria, 2012.

[11] B. Masoud. Modeling and Controller Design of a Wind Energy Conversion System Including a Matrix Converter. Thesis $\mathrm{PhD}$ in Electrical and Computer Engineering, University of Waterloo, Ontario, Canada, 2008.

[12] I. V. d. Hoven, "Power Spectrum of Horizontal Wind Speed in Frequency Range from 0.0007 to 900 cycles per hour”, Journal of Meteorology, (1957), Vol 14, pp 160164.

[13] L.Y. Pao, K.E. Johnson. "A Tutorial on the Dynamics and Control of Wind Turbines and Wind Farms", In American Control Conference, St.Louis (Missouri), USA, 2009.

[14] B. Boukhezzar, L. Lupu, H. Siguerdidjane, and M. Hand, "Multivariable Control Strategy for Variable Speed, Variable Pitch Wind Turbine”, Renewable Energy. (2007), Vol 32, pp 1273-1287.

[15] M.E. González, J. Garrido, F. Morilla, F. Vázquez, "Multivariable Centralized Control with Decoupling and Feedforward Compensation for Residential Wind Turbine”, In $18^{\text {th }}$ IFAC World Congress, Milano, Italy, 2011.

[16] F. Vázquez, F. Morilla, S. Dormido, “Entorno para simulación, análisis y sintonía de sistemas de control descentralizado 2x2”, In XIX Jornadas de Automática, Madrid, Spain, 1999. 